Ilha de Santa Catarina

\title{
Glauber:
}

\section{imagens da vida/obra}

Imagens cedidas por:

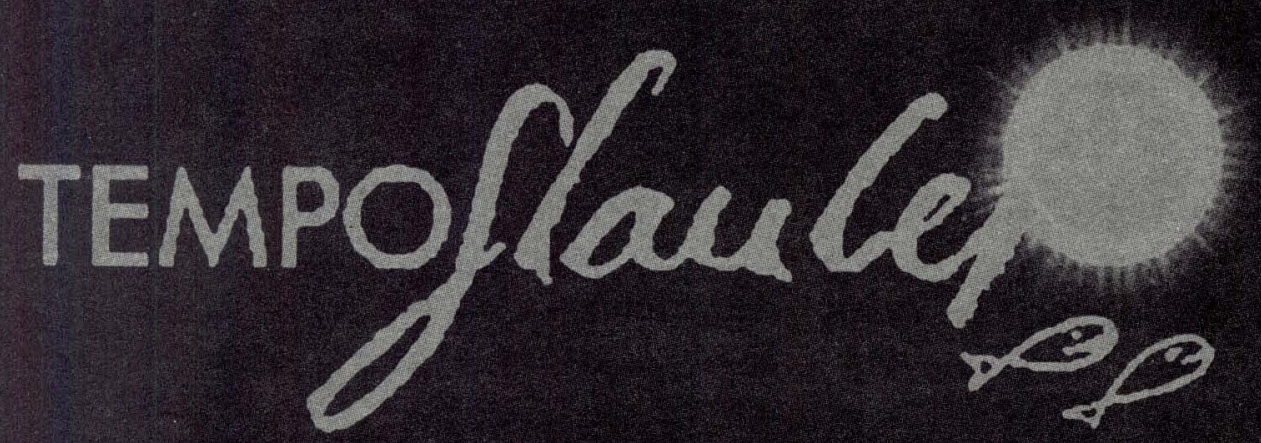

ASSOCIACÃO DOS AMIGOS

DO TEMP0 GLAUBER 


\section{cahiers du}

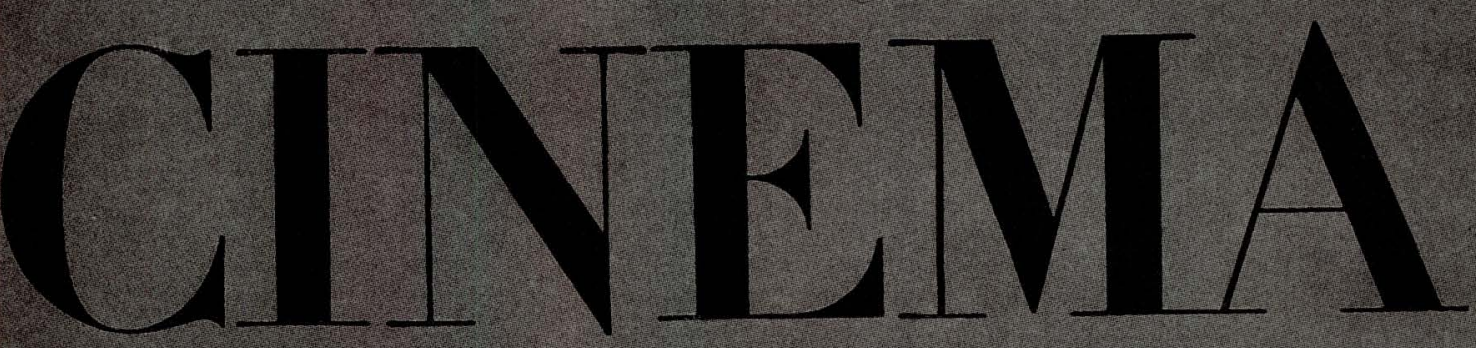

S. M. Eisenstein

Emile De Antonio

Glamber Rocha

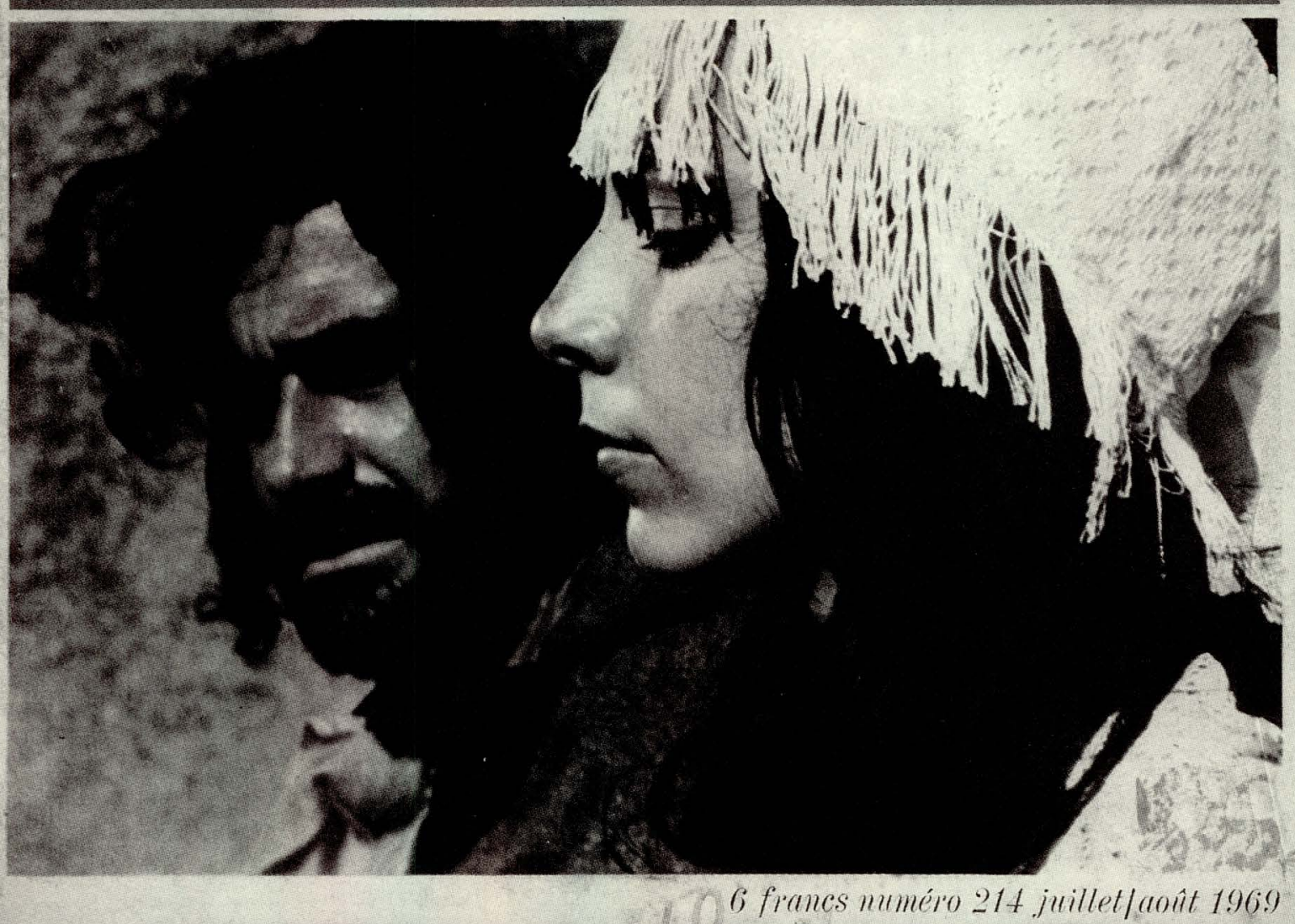




\section{LUIZ AUGUSTO MENDES}

\section{apresenta}

\section{de us \\ e 0 \\ diabo \\ na \\ terra do}
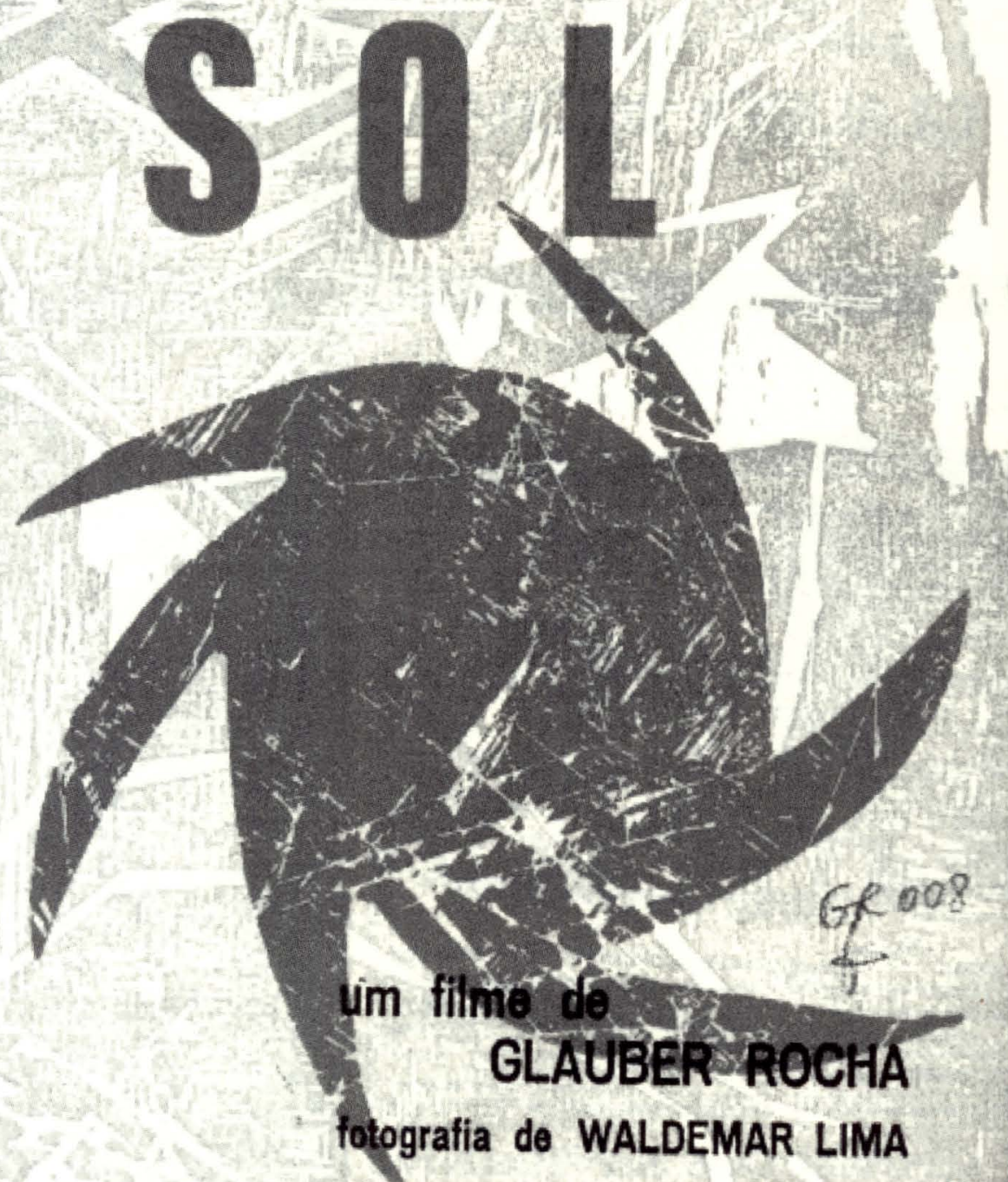


\section{O Século do Cinema}

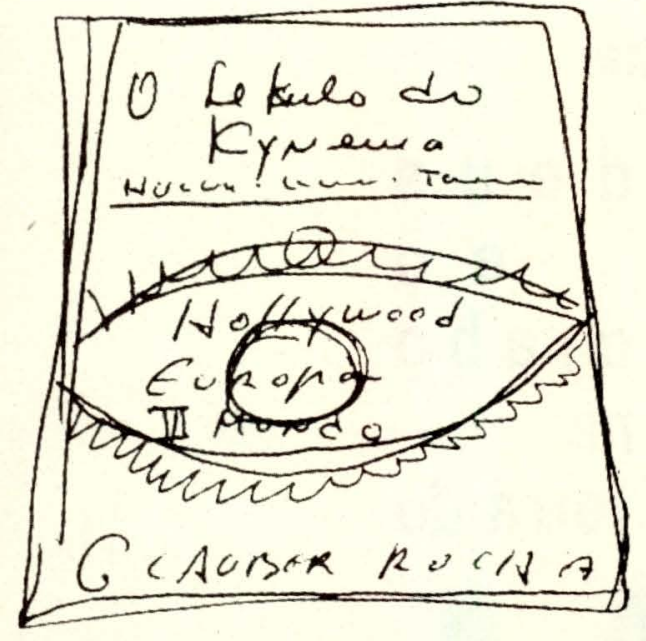

\section{GLAUBER ROCHA}

POEMAS ESKOLHYDOS DE

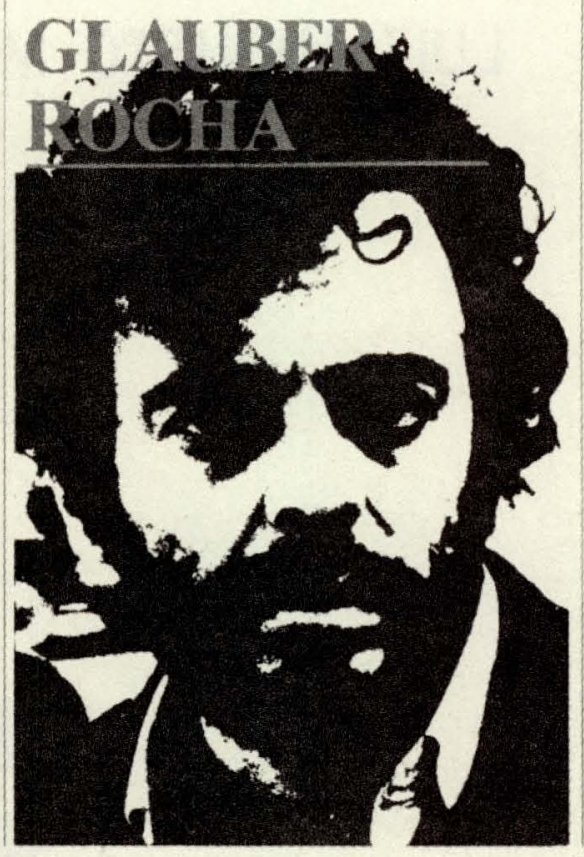

Alhambra

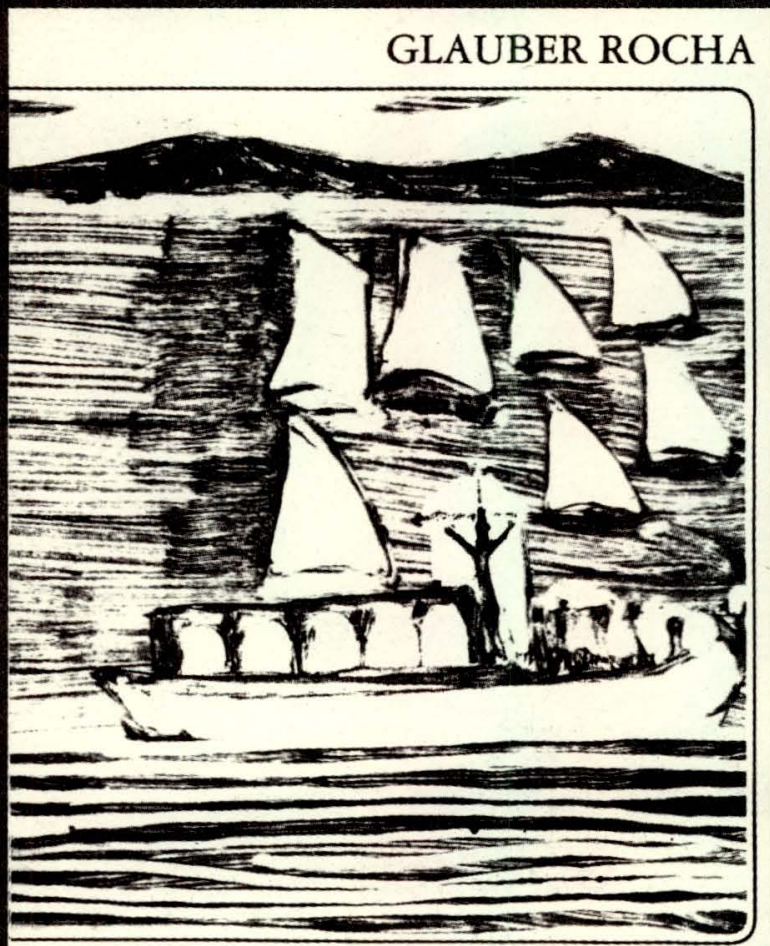

SENHOR DOS NAVEGANTES

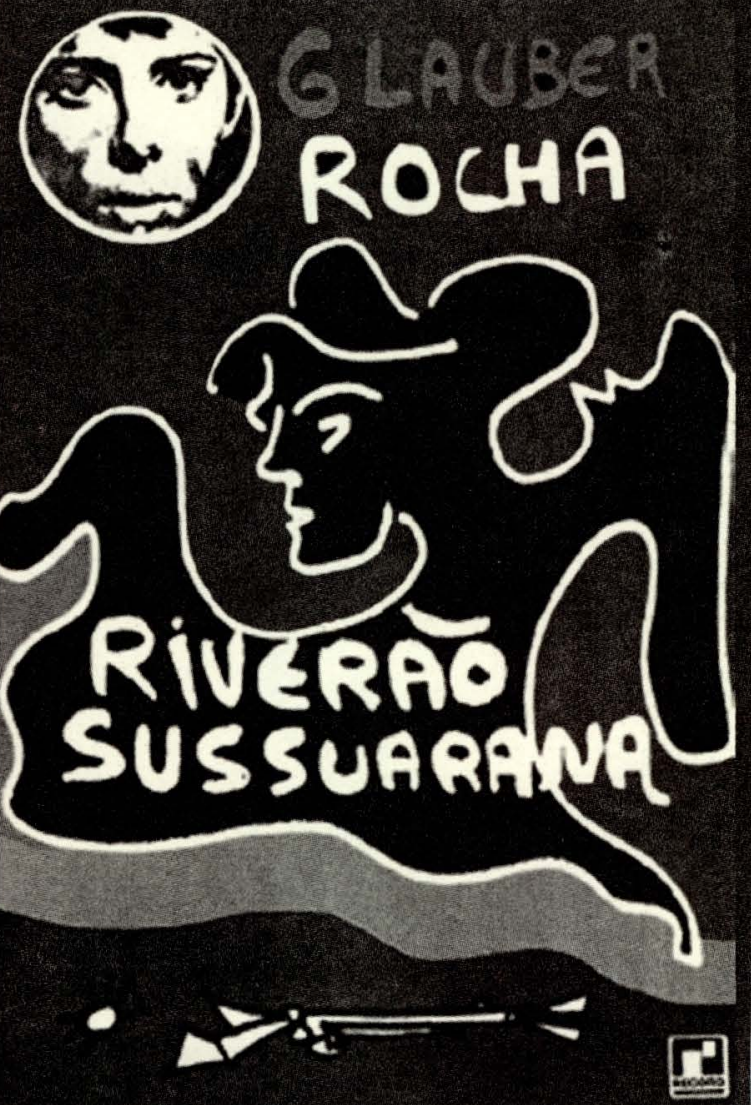




\section{ITha de Santa Catarina}

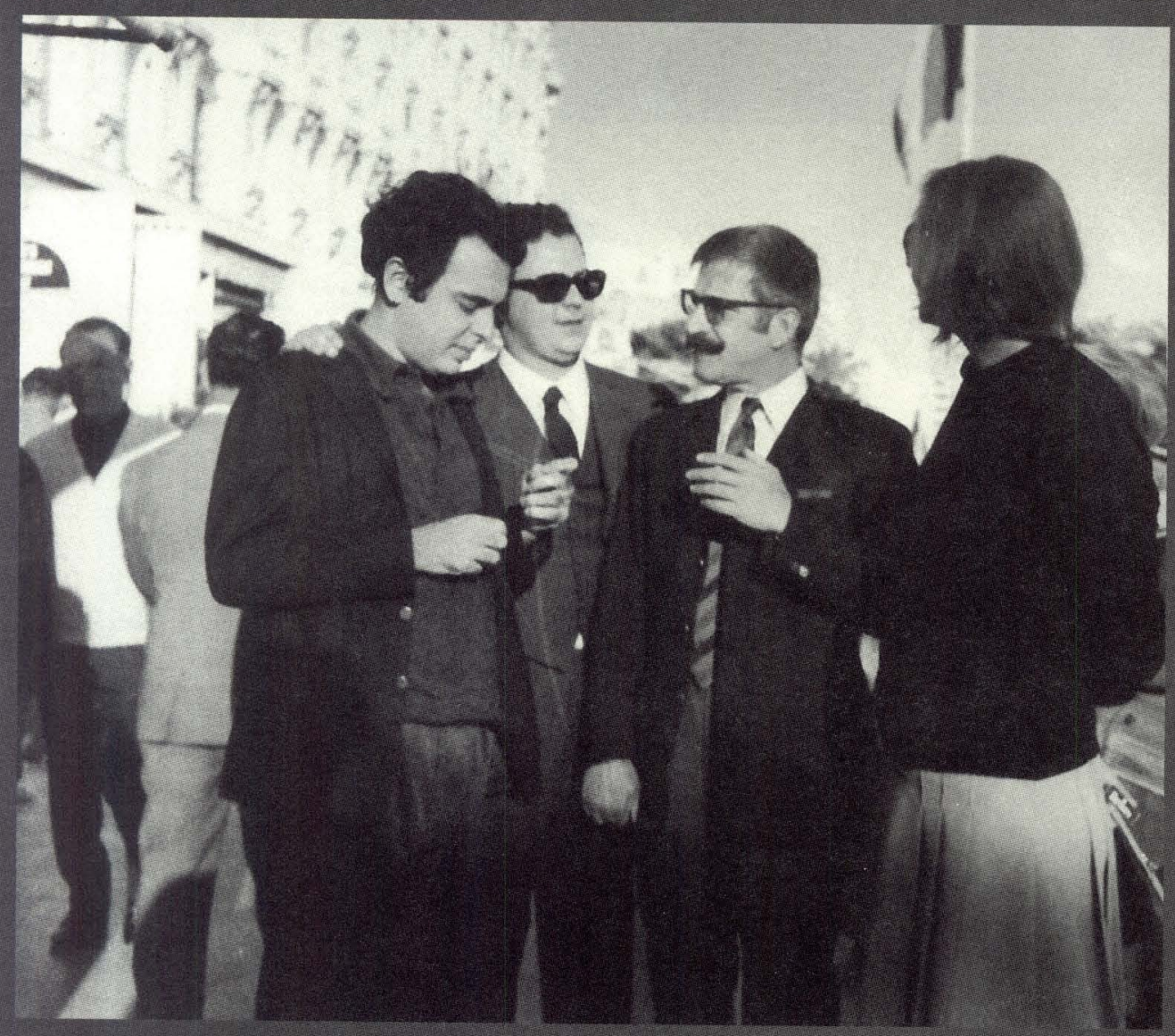



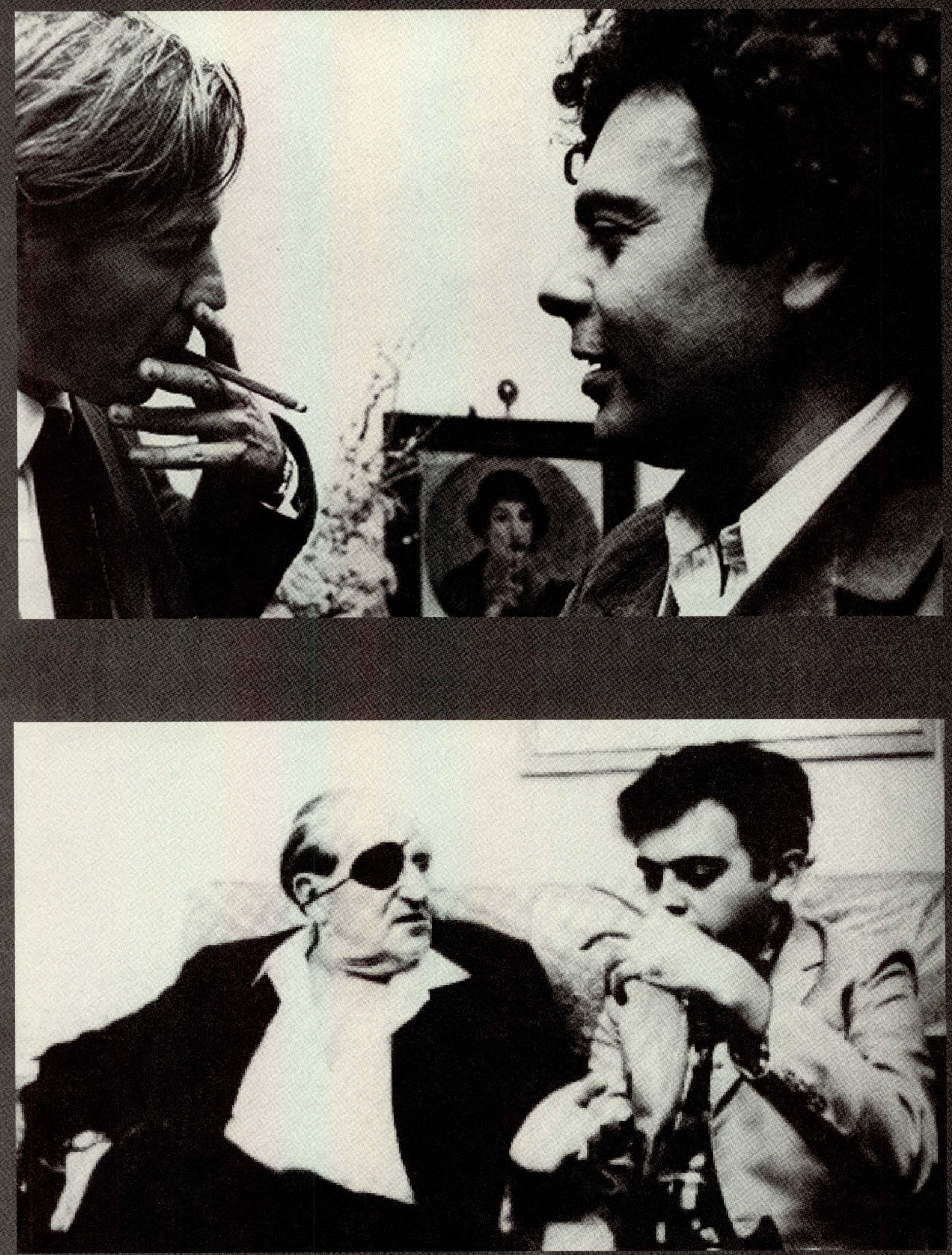

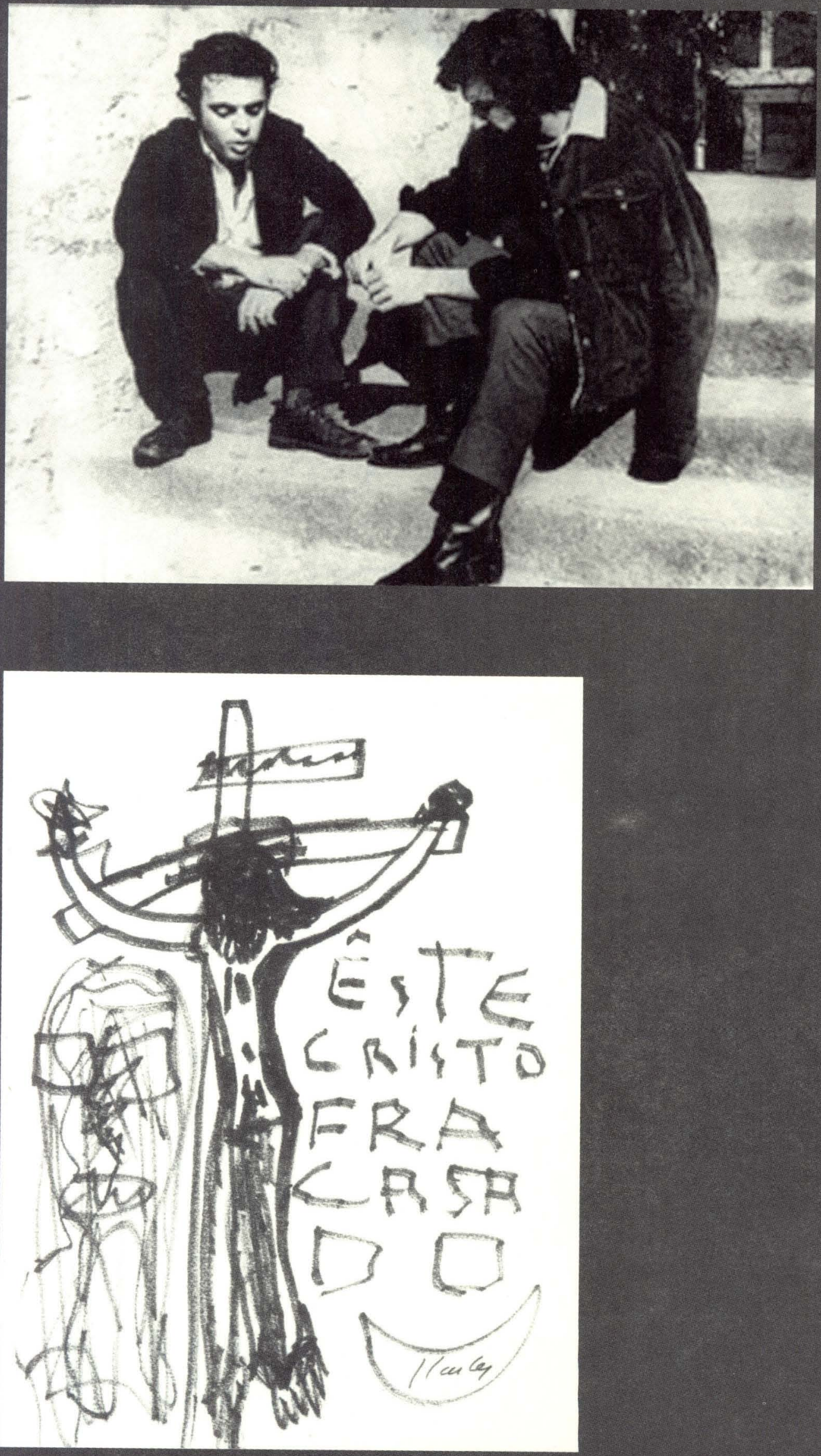

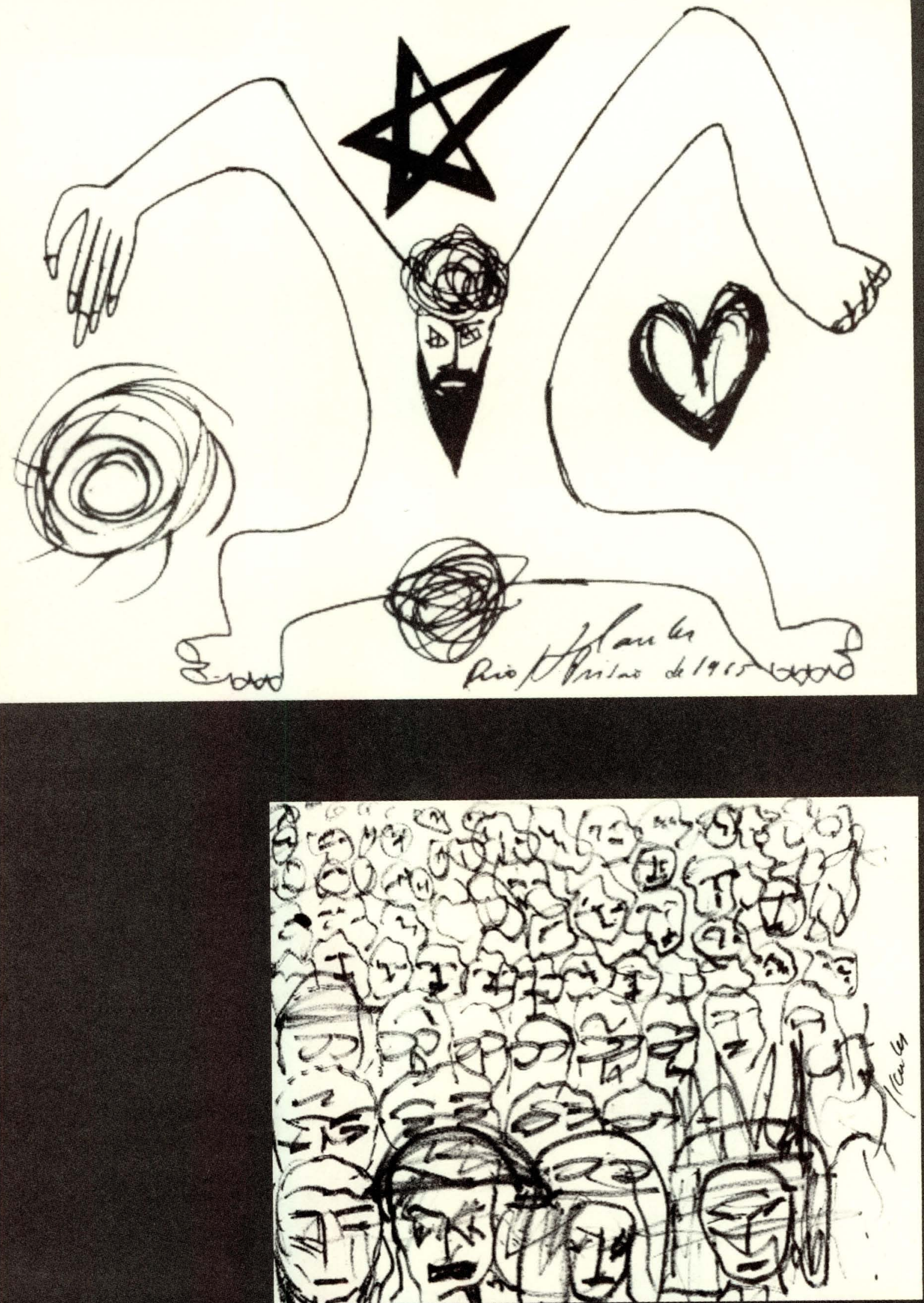


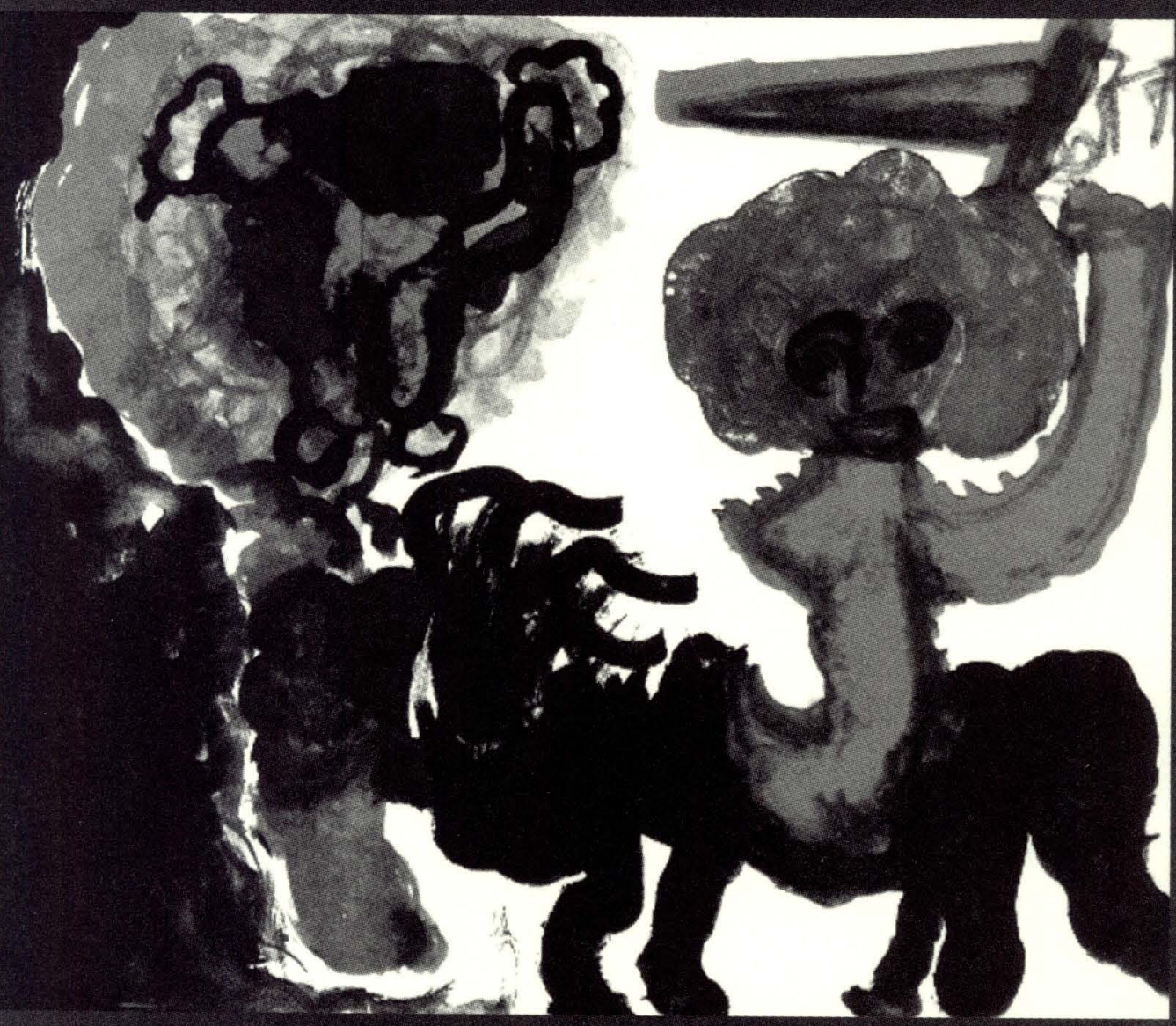

\section{POESIAS CORDEL}

$$
\text { Ink }
$$

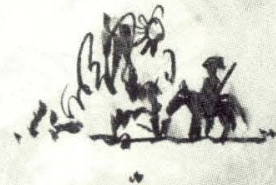

Q CANITO DO NORTESTEE $\alpha$

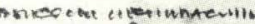

$$
\longrightarrow \text { ? }
$$

Quem diz que na cating depois que a faca saiút No solo sêco do sertaí Corisco gritou do fun A fome do cangaco $\epsilon$ toda oricta danoir 


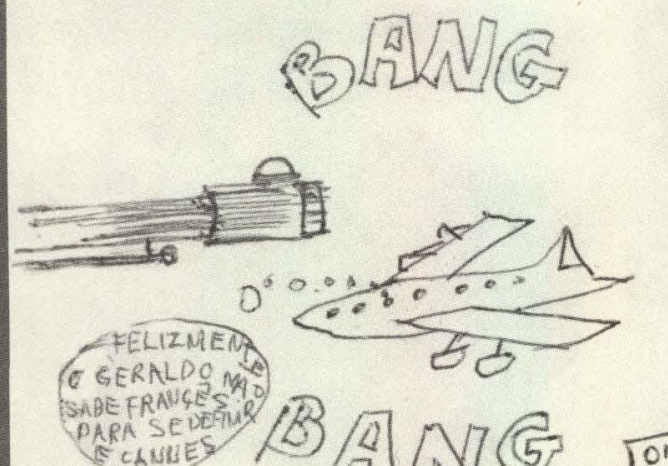

B同果

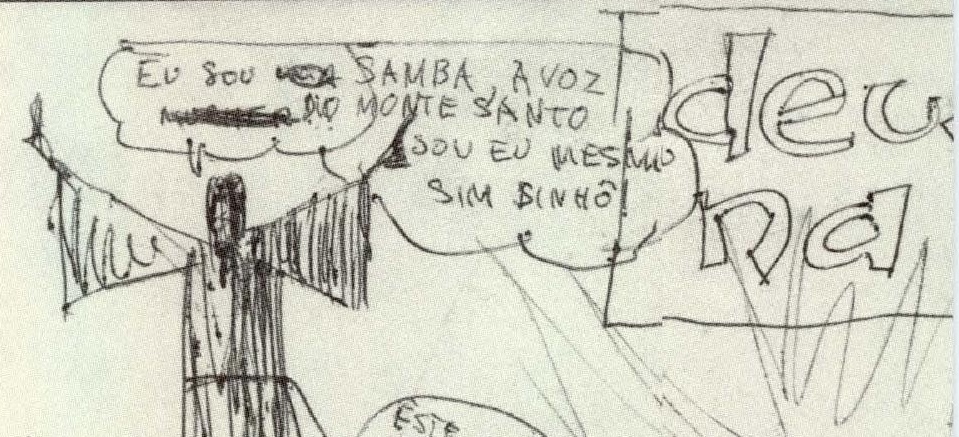

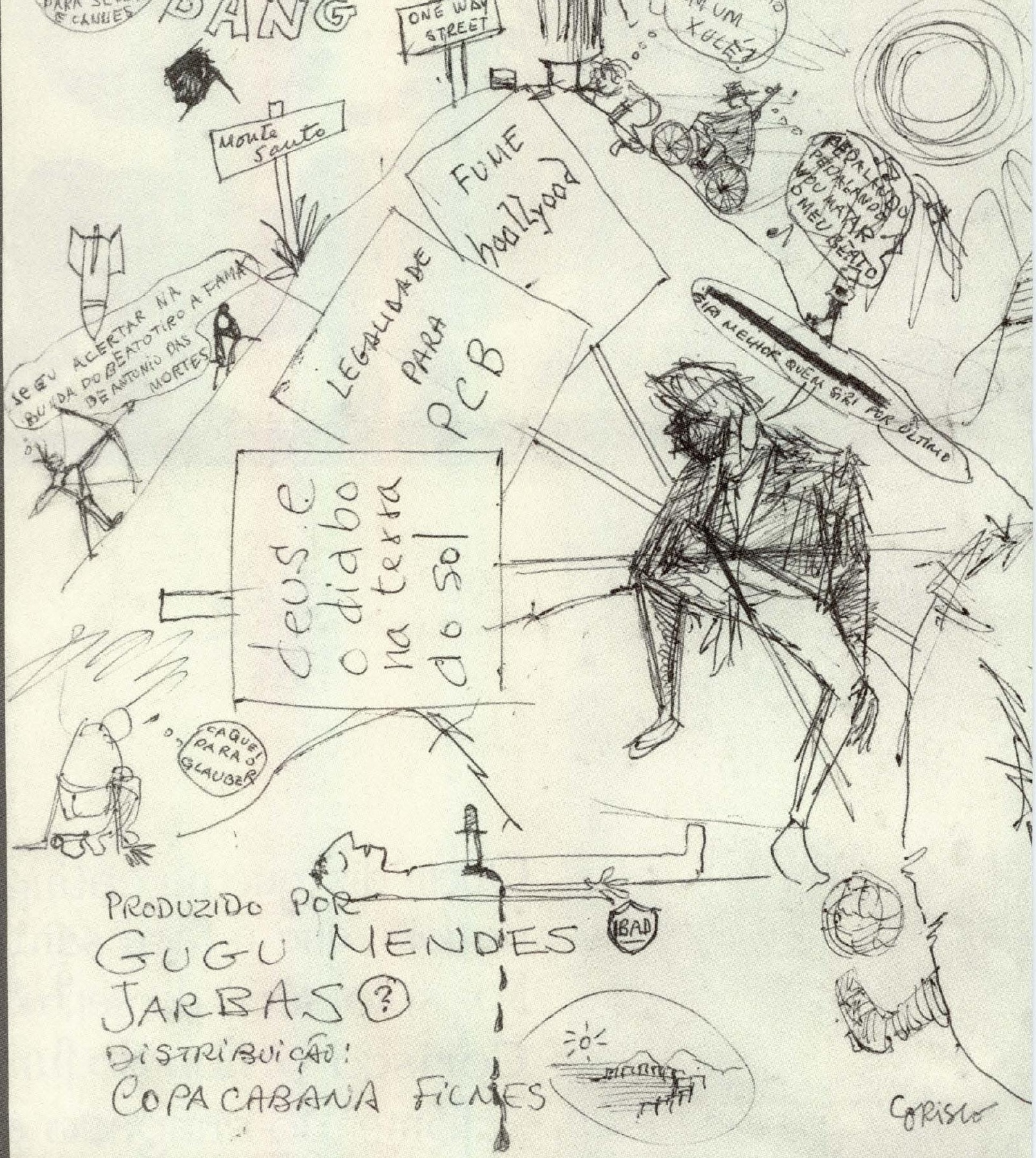



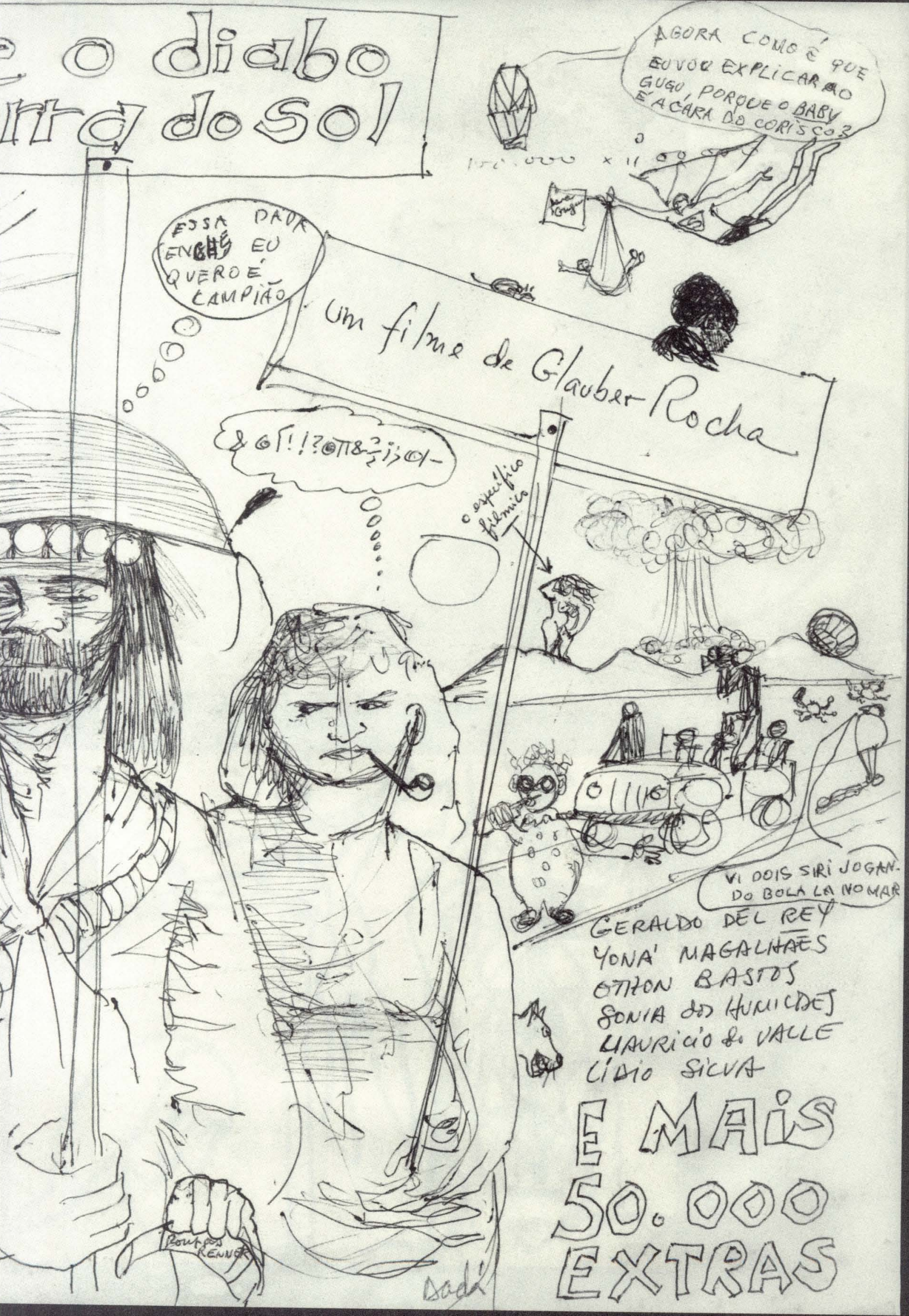

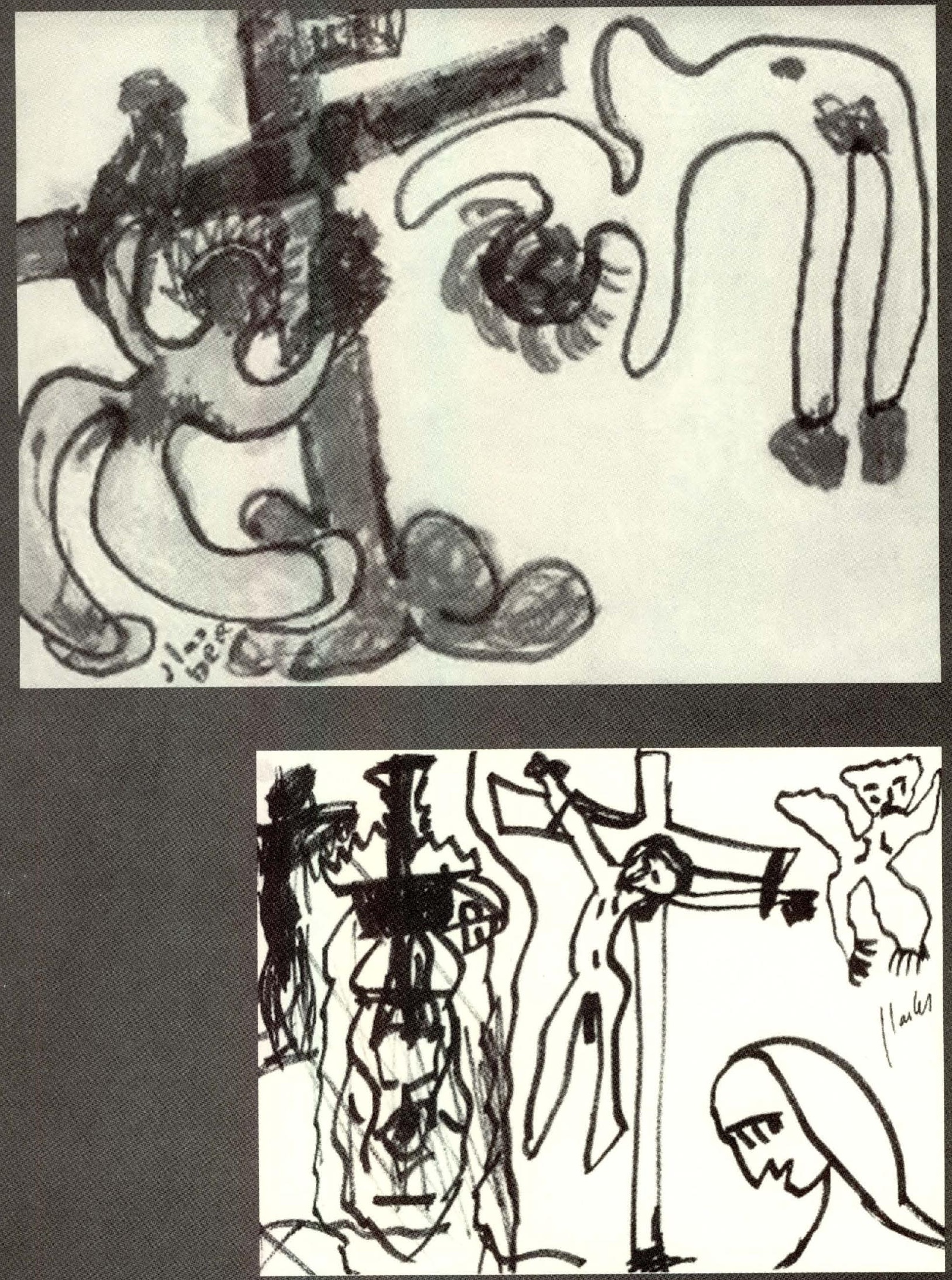


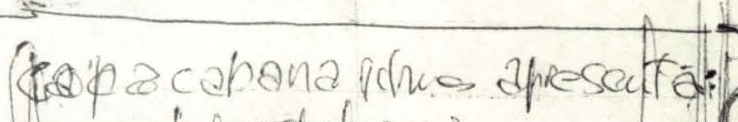
arende del rei

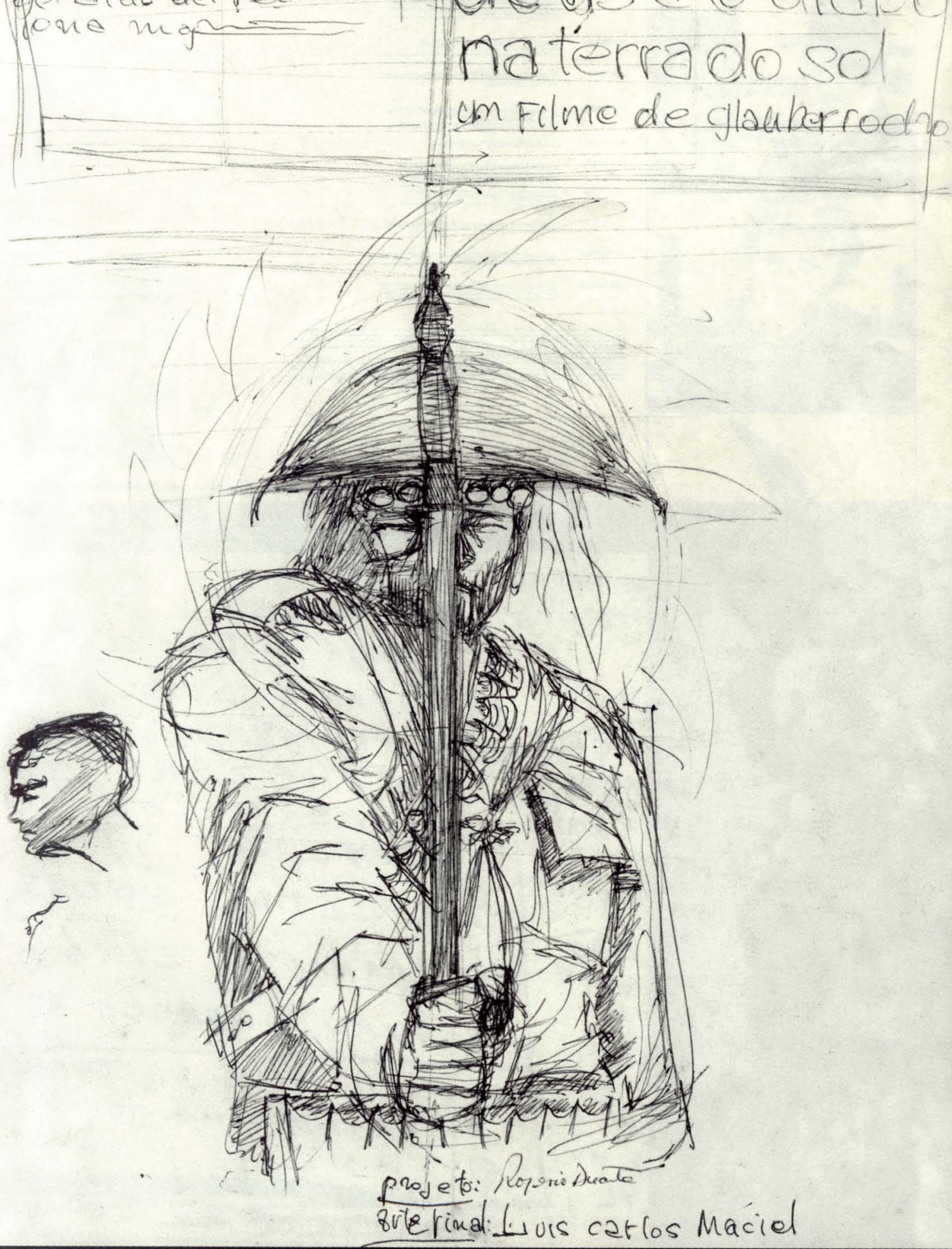




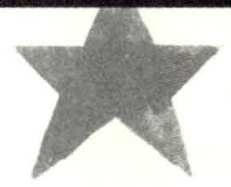

Pracoru-teana

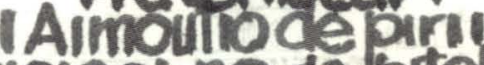

Inicial no dá bilolast

plantumplo lob plonarodas 4

alouns parresem que la uma corsa

daldiabonaterradosol como asurioda

na ollicafia que diz: direaco saidadosc cancaco - fomos alguns para rever oquepo - ods ser felto anies are eles dirajantodasas

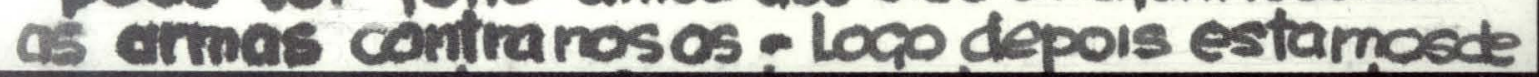

GLauber rocha comunicaçoes artisticas

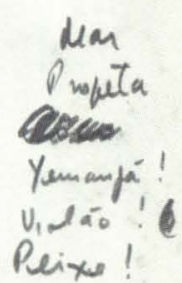

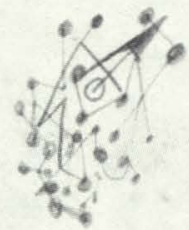

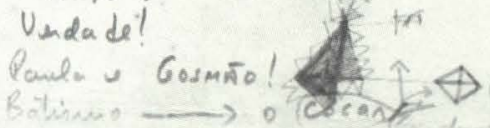

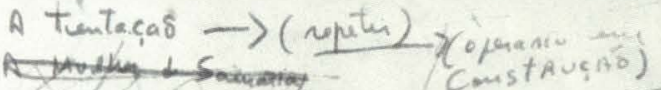

chto to

A Multien de SAMARIA (Sandoval)

(opraic an Constaviso)

(Muther do Samaria)
A setrica que quers contos lot o

titulo de "A "Idade da tena" $\rightarrow$ ou

"O Nancimento da Teina" $\rightarrow$

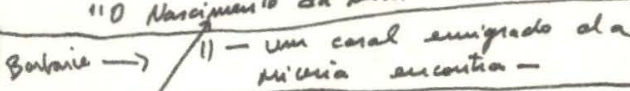

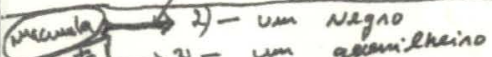

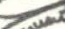

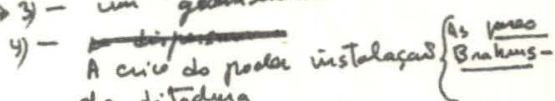
da ditadura

$\eta \rightarrow$ Prisăo $\rightarrow 0$ enquara picitor

7 Pryga

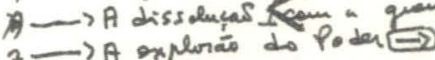

8) $\rightarrow 0$ Praiso -

Geaphyon- getit 
"Anuk - indio) $\longrightarrow$

2) BRAHMS - ZyEmbINSKY -

4) Frederias Viacheli - $L E C E$

7) Carclos - Geralde des Rey.

6) Madalena - Norma

7) BettY - Panla =

8) Punalua - Paloma

9) Mrales - Mannicio dovalle-

10) YanóA- Hancma Monkmi (menuso)

D- Cintoviand Othellom

Pomersanou $\longrightarrow$ gorge prea -

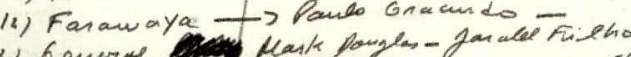

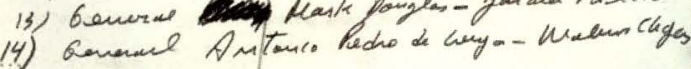

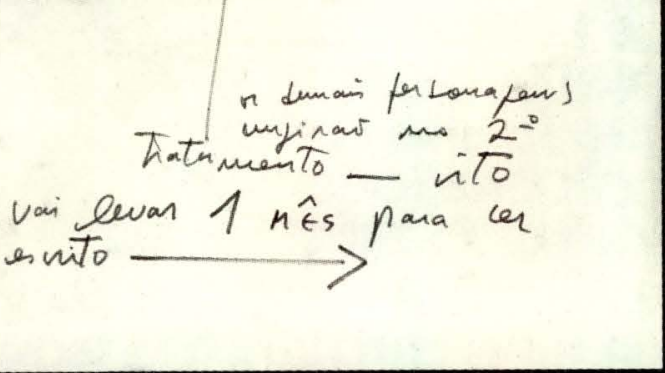

Falta rwerer

(1919) Rovalucin Culana

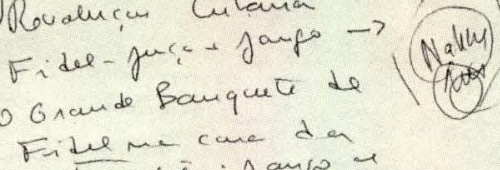

$$
\begin{aligned}
& \text { arciliangecs do derefo } \\
& \text { Ganjo } \\
& \text { II } 1961 \text { china toongitw }
\end{aligned}
$$$$
\text { ganjo con karnody (curenen) }
$$$$
\text { ganjo }
$$$$
\text { jampo ma Fahica } 1962
$$$$
\text { mo fortax } 1963
$$$$
y \text { and wa favela L }
$$ 